\section{THE REALISTIC DILEMMA AND DEVELOPMENT PATH OF THE INTE- GRATION OF PHYSICAL EDUCATION TEACHERS, COACHES AND SOCIAL SPORTS ORGANIZATIONS IN THE INTEGRATION OF SPORTS}

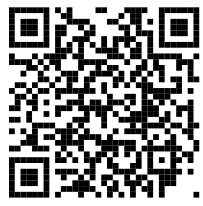

\author{
Wan-Ting $\mathrm{Li}^{1}$ and Li-Wei $\operatorname{Lin}^{2}$ (1) \\ Zhejiang Normal University, China \\ ${ }^{2}$ The School of International Business, Zhejiang Yuexiu University, No.428 Kuaiji Road, Yue Cheng District, Shaoxing, \\ 312000, China
}

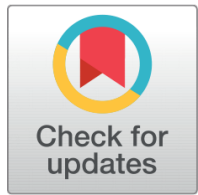

Received 6 June 2021

Accepted 16 June 2021

Published 30 June 2021

Corresponding Author

Li-Wei Lin, linlw1982@gmail.com

DOI $10.29121 /$

granthaalayah.v9.i6.2021.4054

Funding: This research received no specific grant from any funding agency in the public, commercial, or not-for-profit sectors.

Copyright: (C) 2021 The Author(s). This is an open access article distributed under the terms of the Creative Commons Attribution License, which permits unrestricted use, distribution, and reproduction in any medium, provided the original author and source are credited.

\section{ABSTRACT}

The integration of physical education conforms to the needs of powerful countries in education and sports, and conforms to the training and development of young people in the new era. Through the method of literature and interview, this paper summarizes and analyzes the practice of physical education integration in China, analyzes the difficulties existing in the integration of physical education in multi-subject intercommunication and integration, and puts forward the further improvement path.At present, the existing problems mainly include: people's insufficient understanding of the concept of physical education integration; The post system is not clear in the intercommunication of various subjects of physical education and financial system; The teaching or training objectives of each subject are not clear; There are many sports items, the primary and secondary are unclear, and the hierarchy is chaotic. The professional ability and knowledge level of each main body are not uniform; Therefore, it is necessary to take measures to deeply implement the concept of physical education to improve the cognition of physical education integration. To establish a system of cooperative governance of multiple subjects integrating physical education; Establish teaching standards at all levels, and clarify teaching objectives and requirements; Establishing a training service platform for sports and education integration with big data; To increase the pilot of physical education integration in order to speed up the implementation process of physical education integration in China, to better train the socialist builders and successors who develop morally, intellectually, physically, aesthetically, and labor comprehensively, and to develop the cause of physical education in China.

Keywords: Sports and Education Integration, Physical Education Teachers, Coaches, Social Sports Organizations, Communication 


\section{INTRODUCTION}

In the 13th meeting of the Commission for Deepening Overall Reform of the CPC Central Committee "General Administration Of Sport Of China, Ministry Of Education. About Print And Distribute To Deepen Teaching Fused Promote Adolescent Health Advice To Inform [EB/OL]. (2020-09-21) [2021-01-21]" (n.d.) presided over by Xi Jinping, it was clearly proposed to establish the education concept of health first. It embodies the idea of "education with sports", which requires us to take "cultivating people by virtue" as the fundamental task, focus on promoting the coordinated development of youth cultural learning and physical exercise, strengthen school sports work, improve the system of youth sports events, and highlight the integration of sports and education as the main body of both sports and education. The ultimate goal is to help students enjoy fun in physical exercise, enhance their physique, improve their personality, exercise their will, and cultivate socialist builders and successors with all-round development of moral, intellectual, physical, aesthetic and labor.From that body teach fusion is face our youth and sports enterprise sustainable development the important project, is the school sports, public sports club, youth, youth sports clubs events, sports schools of various levels, such as mutual accommodation, is to promote youth culture learning and sports exercise and the coordinated development of a complex system.In this work, the government, social sports personnel, sports teachers, coaches, researchers, parents and so on are indispensable forces.How to integrate and how to communicate? How to integrate for the development of youth sports?These are going to be very complex issues.

Articles 27 to 29 of Opinions on "Deepening the Integration of Sports and Education to Promote the Healthy Development of Adolescent" put forward the implementation of the policy of part-time sports teachers, requiring schools and sports schools to communicate with each other in terms of culture, sports teachers and coaches.We will set up posts for coaches in schools and set up a system for elite retired athletes to enter the campus. "General Administration Of Sport Of China, Ministry Of Education. On Deepening Teaching Fused Opinions To Promote The Development Of Adolescent Health [EB/OL]. (2020-09-21) [2021-01-21]" (n.d.) Let outstanding retired athletes serve as teachers of the school; The coaches of the sports school work as coaches in the school; School culture teachers to the sports school teaching service, so as to promote the physical education teachers mutual benefit, improve the overall quality of full-time coaches. Mingyi et al. (n.d.)It can be seen that the national policies and requirements for physical education teachers and coaches in the integration of physical education. In this study, a total of 20 physical education teachers, sports school coaches, retired athletes, and practitioners of social sports and sports related organizations were interviewed by using the research methods of literature and interview. The problems encountered by them under the model and policy of integration of physical education and sports were summarized and corresponding strategies were proposed. 
In order to break the bottleneck of the integration of sports and education, the Opinions put forward reform measures for the remuneration of PE teachers in ordinary schools, coaches in sports schools at all levels and all kinds of sports schools, coaches in sports schools at all levels and retired athletes entering colleges and universities.However, in the process of implementation and practice, there are still many difficulties, and the national government and society need to further refine the implementation of policies and measures.In order to ensure the authenticity and validity of the study, the author conducted interviews with relevant personnel (relevant leaders of primary and secondary schools, directors of physical education group, physical education teachers, social sports activity organizations, sports school coaches, social sports workers, volunteer service teams, etc.) through visits, telephone and network contact. This paper analyzes the current situation of the integration of physical education and its common problems and causes, discusses and communicates with them, and puts forward practical suggestions and solutions.

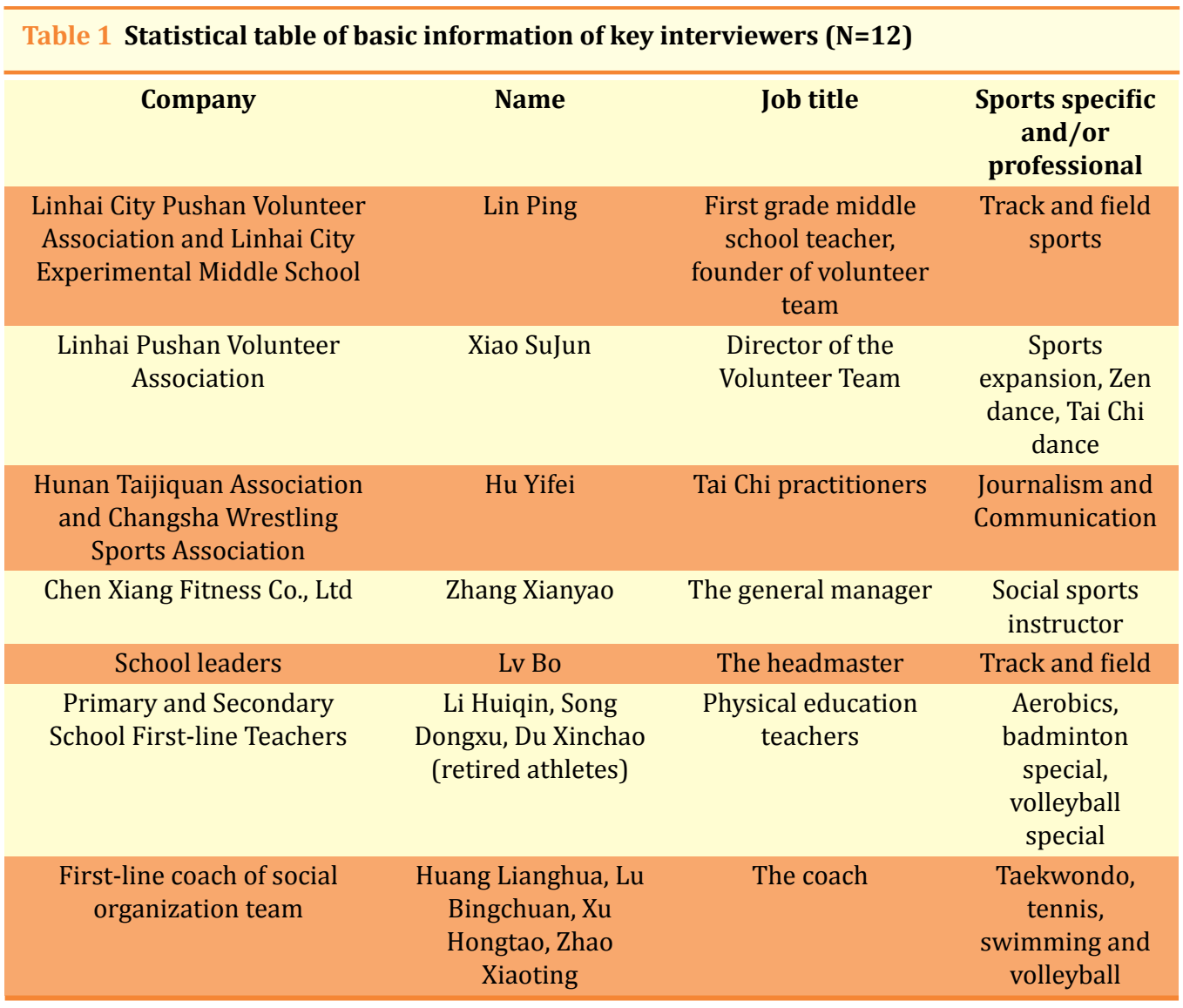




\section{DIFFICULTIES FACING}

\subsection{PHYSICAL EDUCATION INTEGRATION CONCEPT UNDERSTANDING IS INSUFFICIENT, THE TRANSFORMATION OF THE CONCEPT IS DIFFICULT}

Interviewees found it difficult to change their ideas, which were mainly reflected in the following three aspects: First, it was difficult for leaders at the university level to change their ideas. Some physical education teachers put forward that if they do foreign coaches, the sports performance of the students from other schools is better than that of the students in the school, the school leaders will exert pressure. Because this school student sports performance is related to the reputation of the school and the quality of enrollment. Second, it is difficult to change social ideas. Because in school teachers make up lessons outside not only by the national policy strict restrictions, but also by the social opposition. Some PE teachers said that although the state policy now allows PE teachers to go to sports schools, clubs, public venues and other teaching and guidance, but this situation is generally not open, basically private. Teachers tend to be more willing to participate if they are taught by the public, but if they are taught privately, they tend to resist because of the negative impact, whether it is for profit or public service. In order to realize the integration of physical education and physical education, the teacher mentioned in the interview that he hoped the country would improve the policy of foreign teaching of physical education teachers, and provide a platform for teaching and guidance abroad, so as to provide a certain guarantee for them. The third is the difficulty of the change of coaches' ideas. Some old coaches, they have rich training experience, but they focus on physical education rather than teaching, for them, through the school physical education and the new curriculum standards for teachers have a certain difficulty.

\subsection{THE POST SYSTEM IS NOT CLEAR IN THE INTERCOMMUNICATION OF VARIOUS SUBJECTS OF PHYSICAL EDUCATION AND FINANCIAL SERVICES}

At present, the policies issued by the Shenzhen Reform Commission mention that coaches from sports schools, social organizations and retired athletes are enrolled in colleges and universities, as well as the establishment of coaches' posts and the payment for extra-curricular activities. "General Administration Of Sport Of China, Ministry Of Education. About Print And Distribute To Deepen Teaching Fused Promote Adolescent Health Advice To Inform [EB/OL]. (2020-09-21) [2021-01-21]" (n.d.)But in the actual process, we found that sports school coaches, physical education teachers, retired athletes do not know the responsibilities of their positions. For example, if a physical education teacher works as a sports school teacher, should he focus on the sports skills of the students in the sports school or on educating the students? Should we make teaching plan according to the content of the new curriculum standard or copy the previous training plan? Coaches in sports schools and physical edu- 
cation teachers in ordinary schools are two different professions, with different position characteristics, so what should they take as the teaching standard in the process of teaching? Is the goal of entering a coaching position to improve the athletic performance of school athletes or to train physical education teachers? Or both? What are the positions of PE teachers, social sports organizations and sports school coaches when they communicate with each other? What are the criteria by which their work will be evaluated? This series of problems, is the main body of the post responsibility is not clear, the evaluation system is not complete, personnel allocation is unfounded.

\subsection{DIFFERENT TEACHING OR TRAINING OBJECTIVES LEAD TO THE CONFUSION OF TEACHING OR TRAINING MODE}

The teaching objectives of PE teachers are different from those of coaches in sports schools and social clubs at all levels. The teaching objectives of PE teachers in schools are mainly divided into three objectives: knowledge and skills, process and method, emotion and values. The teacher designs the teaching content according to the requirements of the course standard and the actual situation of the students. However, the coaches of sports schools at all levels, their training goal is mainly the athletic performance of the players, they pay more attention to the results of each competition and the development of the players' physical and mental functions. The coaches in clubs and some social sports organizations are mainly to cultivate the players' interests and hobbies and master their sports skills. Because of the different training objectives, they design different teaching content. Then different teaching modes and training methods will produce different teaching and training results. The main reason for this problem is that there is no reference standard, requirement and specific target for each post in the system of integration of physical education, which leads to the failure of these subjects to clarify their teaching objectives, work objectives and work tasks in this system, and finally leads to difficulties in the transformation of teaching or training mode. Zhenling (2020)

\subsection{VARIOUS SPORTS, UNCLEAR PRIMARY AND SECONDARY, HIERARCHY CHAOS}

Under the new curriculum standard, there are 6 sports items as the national new curriculum standard, which are track and field, gymnastics, football, volleyball, martial arts and gymnastics. Each of these six items is made up of different child objects. Take martial arts for example. According to the content of martial arts, it includes taijiquan, long boxing, youth boxing, five step boxing and so on.Therefore, in this system of physical education integration, there is no clear regulation on which projects are carried out as the adaptation points of physical education integration, which easily leads to a large number of physical education integration projects in practice, and schools are prone to lose their direction when recruiting talents. Another example is the sports in some traditional characteristic schools, such as dragon boat, can it be used as the integration of physical education?For another example, some colleges 
and universities have set up the post of Taijiquan Consultant. Most of these posts are held by Taijiquan masters, so they usually have their own training system and follow the tradition. When they enter the school, they will find that the teaching content of Taijiquan in the school is not systematic, there is no clear teaching target system, and they can not go deep into the teaching.Because the learning of Taijiquan is a longterm process, it will have different levels of change, the short-term teaching effect is not obvious. So these problems can not be solved for their teaching to bring certain difficulty. In addition, Tai Chi consultant is an auxiliary position in the schools in the test sites, helping the schools guide the spread of Tai Chi and movement techniques. Physical education teachers still take the lead in the actual courses, and Tai Chi is also taken as an elective course in the curriculum planning.This shows that schools pay little attention to the study of Taijiquan is difficult to go deep. In some schools, coaches have been established, but there is no specific job responsibility and purpose. All the staff's work is to teach and teach according to the requirements of their original posts, and the concept of integrating physical education has not been deeply integrated and implemented.For example, the coaches who enter the school think that they just change places to work, and their role is only to improve the performance of high-level athletes and the training of the club, but not to promote the ordinary physical education curriculum.

\subsection{THE LEVEL OF PROFESSIONAL COMPETENCE AND KNOWLEDGE IS UNEVEN}

Physical education teachers in schools, coaches in social sports organizations and practitioners of sports projects all have their own shortcomings. First of all, the coaches of social sports organizations and the practitioners of sports projects, who lack relevant experience, sometimes find it difficult to follow the general rules of teaching. Luping et al. (n.d.) Unlike the physical education teachers in school, they have all completed the national teacher certification examination and on-the-job training, and basically have the ability to become a people's teacher in all aspects and have certain teaching skills. In addition, coaches in sports schools and social organizations are basically good at something. For example, a swimming coach can teach swimming, but if he is asked to teach football, basketball and volleyball, he will have no idea how to start and cannot be competent for all the teaching contents under the class standard. Secondly, according to the feedback of PE teachers themselves, their experience in leading training teams and their level of motor skills are insufficient. Because most PE teachers are normal university students, the course during the university study is mainly to master the classroom teaching ability, their level of sports skills is general, lack of experience in leading the training team. 


\subsection{THE POLICY OF INTEGRATION OF SPORTS AND EDUCATION WAS IMPLEMENTED SLOWLY AND COVERED LESS}

During the interview, the author found that the units where the interviewees worked did not have explicit regulations on the integration of sports and education, but there were relevant measures in practice. For example, some school clubs and societies cooperate with social clubs, and the field and coaches are shared. None of the units interviewed belonged to the experimental site of physical education integration. Only the volunteer service platform of one school had relevant contents in the implementation of physical education integration, but the process was slow. The main reasons are that the nature of personnel is single (students' parents), frequent replacement; Lack of personnel and management difficulties lead to the slow development of volunteer services. Students' parents have too many uncertain factors, such as job reasons, children reasons, knowledge level reasons and so on.For example, if their children graduate, most parents will leave the group.

\section{THE DEVELOPMENT STRATEGY}

\subsection{IMPLEMENT CONCEPTS THOROUGHLY AND ENHANCE THE COGNITION OF INTEGRATION OF PHYSICAL EDUCATION}

The transformation of the idea of integrating physical education needs the joint efforts of the whole society. Bingshu (n.d.) First of all, new media can be used to disseminate the importance of the integration of sports and education, and carry out the dissemination of sports and health knowledge in schools, communities and sports activity organizations. While building the whole society to actively carry out sports activities and sports, each education and sports system should also change the traditional and single goal of improving sports skills. Focusing on the all-round development of moral, intellectual, physical, aesthetic and labor of young people and the development of social sports undertakings, the center of gravity and focus on helping students enjoy fun in physical exercise, enhance their physique, improve their personality and exercise their will, so as to cultivate a socialist builder and successor with all-round development of labor in the new era. "General Administration Of Sport Of China, Ministry Of Education. About Print And Distribute To Deepen Teaching Fused Promote Adolescent Health Advice To Inform [EB/OL]. (2020-09-21) [202101-21]" (n.d.)

\subsection{ESTABLISH A SYSTEM OF COOPERATIVE GOVERNANCE OF MULTIPLE SUBJECTS INTEGRATING SPORTS AND EDUCATION}

Professor Zhong pointed out that physical education and education need to be integrated in the mechanism of the integration of physical education, and they are inseparable. And from the "thought, goal, resources, measures" four aspects of the integration of detailed analysis of physical education integration of the specific 
mechanism.Therefore, in the multi-subject collaborative governance system of three-dimensional education integration, the local management mechanism should take the government as the core, and under the leadership of the local Party organizations, a governance platform for joint decision-making and management by various schools, sports activity organizations, local volunteer associations and other multi-subjects. Bingsu (n.d.)First of all, local body education integration should be led by the government or party organizations. At present, it is difficult for the sports system and the education system to integrate rapidly, and it is difficult to unify the work nature of all walks of life in the sports, so the government and the party organization need to coordinate. Secondly, the integration of local sports and education requires the participation and cooperative governance of multiple entities.In the local sports and education integration service system, in addition to the sports department and the sports department, several departments such as finance, civil affairs, volunteers and scientific research should be set up. And set the development plan, goal, policy and authority of each department, which can be used to guide, coordinate, train, supervise and evaluate the implementation of local sports and education integration.Thirdly, through the promulgation of relevant laws and regulations, the establishment of a perfect physical education integration post system. In this process, it is necessary to establish complete job responsibilities Hong and Xianxiong (n.d.), job requirements, job standards, and job evaluation. Determine work objectives, tasks and performance evaluations for each position.Finally, establish clear rules and regulations, reward and punishment mechanism, incentive mechanism. Improve the policy of professional title evaluation, salary and treatment of the amateur training coaches, and narrow the gap with the classmates. Mingyi and Huang (n.d.)

\subsection{ESTABLISH TEACHING STANDARDS AT ALL LEVELS, AND DEFINE TEACHING OBJECTIVES AND REQUIREMENTS}

Physical education integration organizations should formulate corresponding teaching objectives and standards, so that the body of physical education integration service can have reference standards in practice, and be able to clarify its own goals and direction.When PE teachers go out of the campus and integrate with social sports organizations, sports schools and clubs, they should not only respect the special rules of competitive sports training, but also penetrate the thought of competitive education to cultivate students' spirit of unity, cooperation, indomitable struggle and pursuit of excellence. It is necessary not only to improve the level of competitive sports, but also to learn cultural knowledge well, so as to train athletes with ideas, culture and sustainable development. Mingyi et al. (n.d.)Coaches should respect not only the characteristics of physical education but also the general rules of pedagogy when they enter the school. We should respect not only the special law of physical education but also the general law of curriculum and teaching theory. Luping et al. (n.d.)When entering schools, social sports organizations should not only give play to 
their own strengths in organizing and arranging competitions, but also give play to their own characteristics of sports skills and knowledge, so as to help the reform of school sports work and the all-round development of students' morality, intelligence, body, beauty and labor. Jia (2018)

\subsection{ESTABLISH A TRAINING SERVICE PLATFORM FOR PHYSICAL EDUCATION AND BIG DATA RESEARCH AND LEARNING}

Government should rely on the Internet, combining the reality of offline, broaden the channels of access to information, integrated into the physical education system and education system data exchange platform, the development of body to teach the big data space, build a house became wisdom to share knowledge, induction, post recruitment information transfer, inquiry learning training, sports venue set Shared, body teaching volunteer of public service, and other functions of integrated platform. First, screening the service subjects of the fusion of physical education.Because the ultimate target of our body education integration is teenagers, so in the teaching or training, the physical and mental health of teenagers, it is necessary to pay attention to. Dongfang and Xin (n.d.) Therefore, when selecting the service subjects of the integration of physical education and sports, we should formulate standards according to the five aspects of morality, intelligence, physical education, beauty and labor, instead of only focusing on the advantages and characteristics of one aspect of the subjects. In addition, it is necessary to establish a standard rating system and a talent management mechanism.Second, strengthen the integration of physical education and continuing education training. For subjects with sufficient expertise in only one or several aspects, we should foster their strengths and avoid weaknesses, give play to their strengths, tailor teaching programs and training for them according to their respective positions, and finally make them meet the entry standards and thresholds. In addition, for those who have passed the selection, we can provide more professional training according to the job requirements, so as to cultivate interdisciplinary talents of physical education integration. Mingyi et al. (n.d.)

\subsection{TRIALS FOR INTEGRATING SPORTS AND EDUCATION WILL BE INCREASED}

At present, it is the early stage of the integration of physical education, and there are both explicit and implicit deficiencies in many aspects. Therefore, we should increase the pilot of the integration of physical education, and examine and find out the problems in practice. At the same time, it will stimulate the vitality of the market and social organizations, give full play to the decisive role of the market in resource allocation and service process, and mobilize the enthusiasm of the market in the implementation of the integration of sports and education. For example, entrustment management, purchase of services and other ways. 


\section{CONCLUSION}

From the perspective of society, the practice of the integration of sports and education in China meets the needs of the growth of young people at present. It is an important link to promote China to build a strong country in education and sports, and is conducive to the development of China's sports economy and cause. From the school level, the practice of the integration of sports and education in our country is conducive to the increase of physical education teachers, improve the sports skills of physical education teachers, strengthen the construction of high level sports teams, and cultivate excellent sports reserve talents for our country. Bingsu (n.d.)From the perspective of students, the integration of sports and education in China is conducive to the development of extracurricular training, sports competitions and extracurricular activities. However, at present, the social members have insufficient understanding of the concept of integration of physical education; The post responsibilities in the intercommunication of various subjects of physical education and finance are not clear; The ambiguity of teaching and training objectives; In addition, there are many sports, unclear primary and secondary, hierarchy disorder; The level of professional ability and knowledge is not uniform; Sports and education integration of the policy implementation is slow, less coverage and other problems.Therefore, it is necessary to continue to deeply implement the development concept of physical education integration, improve the overall cognition of social members on physical education integration, and increase the pilot of physical education integration. Finally, the system of collaborative governance of multiple subjects with the integration of physical education is established. Establish a training service platform for physical education and big data research and learning.

\section{REFERENCES}

Bingshu, Z. (n.d.). Research On The Way To Improve The System Of Youth Sports Events Under The Background Of Physical Education Integration., 2020, 13-20.

Bingsu, Z. (n.d.). Problems And Prospects: Promoting The Healthy Development Of Adolescents With The Integration Of Physical Education. J]. Journal of Shanghai Institute of Physical Education, 2020(10), 5-12.

Dongfang, H., \& Xin, L. (n.d.). The Logic Of Physical Education Integration In The New Era. J]. Journal Of Beijing Sport University, 201(01), 35-42.

General Administration Of Sport Of China, Ministry Of Education. About Print And Distribute To Deepen Teaching Fused Promote Adolescent Health Advice To Inform [EB/OL]. (2020-09-21) [2021-01-21]. (n.d.). Retrieved from HTTP:Www.Gov.Cn/Zhengceku/ 2020-09-21/Content_5545112.Htm

General Administration Of Sport Of China, Ministry Of Education. On Deepening Teaching Fused Opinions To Promote The Development Of Adolescent Health [EB/OL]. (202009-21) [2021-01-21]. (n.d.). Retrieved from HTTP:Www.Gov.Cn/Zhengceku/2020-09 -21/Content_5545112.Htm

Hong, X., \& Xianxiong, L. (n.d.). Difficulties And Reflections On The Development Of Youth Physical Activities Under The Background Of Physical Education Integration. Physical 
Education Guide, 2021(02), 7-12.

Jia, L. (2018). Practice Exploration And Difficulty Analysis Of Physical Education Integration. J]. School Physical Education, 8(02), 78-80.

Luping, Q., Wei, S., Bo, L., \& Al, E. (n.d.). Research On The Linkage Mechanism Of Sports Traditional Characteristic School And Youth Amateur Club From The Perspective Of Sports Education Integration. J]. Journal Of Tianjin Institute Of Physical Education, 201, 3-3.

Mingyi, L., Haipei, G., \& Al, H. Y. E. (n.d.). Integration Of Sports And Education: Mission Of The Times, International Mirror And Chinese Plan. Journal of Wuhan Institute Of Physical Education, 2020(10), 5-14.

Mingyi, L., \& Huang, D. (n.d.). Top-Level Design, Policy Guidance And Promotion Path Of Sports And Education Integration In China. J]. Journal Of Shanghai University Of Physical Education, 2020(10), 13-27.

Zhenling, Z. (2020). Research On The Reform Path Of School Physical Education Under The Background Of Physical Education Integration., 20, 59-60. 